\title{
Graphite Felt Anode Modified by Electropolymerization of Nano- Polypyrrole to Improve Microbial Fuel Cell (MFC) Production of Bioelectricity
}

\author{
Meiling Chi ${ }^{1}$, Huanhuan $\mathrm{He}^{1}$, Hongyu Wang ${ }^{1}$, Minghua Zhou ${ }^{1 *}$ and Tingyue $\mathrm{Gu}^{2}$ \\ ${ }^{1}$ Key Laboratory of Pollution Process and Environmental Criteria, Ministry of Education, Tianjin Key Laboratory of Urban Ecology Environmental Remediation and \\ Pollution Control, College of Environmental Science and Engineering, Nankai University, Tianjin 300071, China
}

${ }^{2}$ Department of Chemical and Biomolecular Engineering, Ohio University, Athens, $\mathrm{OH} 45701$, USA

\begin{abstract}
Microbial Fuel Cells (MFCs) have emerged as a potential technology for direct bioelectricity production from organic matters in wastewater streams that are otherwise unutilized. The graphite felt anode modification by nanopolypyrrole (nano-PPy) was carried out via electropolymerization reaction using cyclic voltammetry (CV). The electropolymerization trials designated PPy-1, PPy-2 and PPy-3 used 5, 10 and $20 \mathrm{CV}$ cycles, respectively with a scanning voltage ranged from 0 to $0.9 \mathrm{~V}$ at a rate of $50 \mathrm{mV} / \mathrm{s}$. The influences of reaction time (reflected by the number of cycles of $\mathrm{CV}$ ) on the morphology of the polypyrrole films on the anodes and the MFC performance were investigated. The polypyrrole film thickness and particle diameter increased with reaction time. Using the PPy-2 anode, the maximum power density was $430 \mathrm{~mW} / \mathrm{m}^{2}$, a $15 \%$ increase compared with that of the control (i.e., MFC with an unmodified anode). Furthermore, the Coulombic efficiency and Chemical Oxygen Demand (COD) removal also increased after the anode modification.
\end{abstract}

Keywords: Microbial fuel cell; Bioenergy; Anode modification; Nano-polypyrrole; Electropolymerization; Power generation; Coulombic efficiency

\section{Introduction}

In recent years, with growing global population and prosperity in many developing countries, the energy crisis and environmental problems such as air and water pollutions have become increasingly pressing for politicians and researchers. It is desirable to harvest the energy in the chemical bonds of the organic matters during wastewater treatment. This kind of low-grade biomass is usually unutilized and often a burden to wastewater treatment facilities. Microbial Fuel Cells (MFCs) are an potential technology that uses microbial biofilms to convert the chemical energy in chemical bonds of the organic matters into bioelectricity $[1,2]$. Therefore, MFCs have attracted considerable attentions in recent years in the academic circle for potential applications in wastewater treatment with concomitant energy production. However, major technological breakthroughs are needed to increase the efficiency and power density before MFCs become practical $[3,4]$.

The electrode material, especially the anode material is a key factor on MFC performance and cost [4,5]. At present, carbon-based materials such as carbon cloth and carbon paper are adopted in most MFC electrodes because of their very low costs, excellent electrical conductivity, non-corrosiveness, and good biocompatibility [4-6]. Several physical and chemical methods for anode modifications such as acid oxidation, ammonia treatment and electrochemical oxidation have been explored [7-9] and found to promote the electron transfer by the anodic biofilm to the anode, resulting in improved power densities in MFCs [10].

Conductive polymers can be used to promote the electron transfer in MFCs. Among all the conductive polymers investigated so far, nano-polypyrrole (nano-PPy) is one of the most attractive materials due to its excellent conductivity, stability and biocompatibility [11]. Zou et al. [12] used a chemical oxidation reaction to synthesize polypyrrole and found enhanced electron collection by the anode from a photosynthetic biofilm in a sun-powered MFC. Feng et al. [13] modified both the anode and the cathode to form a conductive polypyrrole (PPy)/anthraquinone-2,6-disulfonate (AQDS) film to boost MFC performance, and found the modification increased $\mathrm{H}_{2} \mathrm{O}_{2}$ generation and thus enhanced the oxidative ability of the electroFenton process. PPy could be synthesized by either conventional chemical oxidation or electropolymerization [14]. Compared with the chemical oxidation method, electropolymerization is simple, lowcost and quantifiable, making it a convenient and effective method for electrode modification.

In this work, graphite felt anodes were modified by nanopolypyrrole through an electricpolymerization reaction using cyclic voltammetry $(\mathrm{CV})$. The effects of reaction time (indicated by the number of $\mathrm{CV}$ cycles) on the morphology of polypyrrole and on the MFC performance were investigated.

\section{Experimental Methods}

\section{Modification of anodes}

Graphite felt (Jilin Carbon Plant, China) was used to make the anodes. It was soaked in acetone overnight and rinsed with water before being used as the "unmodified" or the "control" anode material.

${ }^{*}$ Corresponding author: Minghua Zhou, Key Laboratory of Pollution Process and Environmental Criteria, Ministry of Education, Tianjin Key Laboratory of Urban Ecology Environmental Remediation and Pollution Control, College of Environmental Science and Engineering, Nankai University, Tianjin 300071, China, Tel: +86 22 23507800; Fax: +86 22 23507800; E-mail: zhoumh@nankai.edu.cn

Received April 02, 2013; Accepted April 25, 2013; Published April 29, 2013

Citation: Chi M, He H, Wang H, Zhou M, Gu T (2013) Graphite Felt Anode Modified by Electropolymerization of Nano-Polypyrrole to Improve Microbial Fue Cell (MFC) Production of Bioelectricity. J Microb Biochem Technol S12: 004. doi:10.4172/1948-5948.S12-004

Copyright: (c) 2013 Chi M, et al. This is an open-access article distributed unde the terms of the Creative Commons Attribution License, which permits unrestricted use, distribution, and reproduction in any medium, provided the original author and source are credited 
Citation: Chi M, He H, Wang H, Zhou M, Gu T (2013) Graphite Felt Anode Modified by Electropolymerization of Nano-Polypyrrole to Improve Microbial Fuel Cell (MFC) Production of Bioelectricity. J Microb Biochem Technol S12: 004. doi:10.4172/1948-5948.S12-004

Electropolymerization was carried out through CV scan in a threeelectrode system with unmodified anode as the working electrode, a saturated calomel electrode (SCE) as the reference electrode, and a graphite rod as the counter electrode and at $5^{\circ} \mathrm{C}$ in an anaerobic chamber. The electrolyte solution was a mixture of pyrrole, high chlorine acid lithium, soluble starch and phosphate buffer. The scanning voltage ranged from 0 to $0.9 \mathrm{~V}$ at a rate of $50 \mathrm{mV} / \mathrm{s}$. The graphite felt was modified by nano-PPy through the electropolymerization reaction using CV with 5, 10, 20 cycles resulting in anodes designated as PPy1, PPy-2 and PPy-3 anodes, respectively. All modified anodes were cleaned with distilled water three times before being used in MFCs. All MFCs were operated under the same operating conditions.

\section{MFC reactor operation}

Single-chamber MFCs with an air-cathode were constructed as described by Cheng et al. [15]. They were operated in batch mode. Each reactor had an anolyte volume of $14 \mathrm{~mL}$. The distance between the anode and the cathode was $2 \mathrm{~cm}$. Four MFCs with different anodes (unmodified, PPy-1, PPy-2, PPy-3) and identical cathodes of carbon cloth containing $0.35 \mathrm{mg} / \mathrm{m}^{2}$ Pt catalyst were operated simultaneously. Each MFC was inoculated with a small amount of an anaerobic sludge (20\% anolyte volume) from The TEDA Sewage Treatment Plant (Tianjin, China). The initial anolyte was a $50 \mathrm{mM}$ phosphate buffered nutrient solution $\left(\mathrm{NH}_{4} \mathrm{Cl} 0.31 \mathrm{~g} / \mathrm{L}, \mathrm{KCl} 0.13 \mathrm{~g} / \mathrm{L}, \mathrm{NaH}_{2} \mathrm{PO}_{4} \cdot 2 \mathrm{H}_{2} \mathrm{O}\right.$ $3.32 \mathrm{~g} / \mathrm{L}, \mathrm{Na}_{2} \mathrm{HPO}_{4} \cdot 12 \mathrm{H}_{2} \mathrm{O} 10.36 \mathrm{~g} / \mathrm{L}$; trace minerals and vitamins) containing $1.0 \mathrm{~g} / \mathrm{L}$ glucose as substrate. The reactor underwent a startup period and the voltage output exhibited the typical cyclic behavior while climbing as observed by Zhou et al. [10] in their MFC operations. When two cycles were completed after the voltage started to take off, the MFC operation was considered stable. At this time, the anolyte was emptied and replaced with a new culture medium containing $1.0 \mathrm{~g} / \mathrm{L}$ glucose and $50 \mathrm{mM}$ PBS. This medium replacement usually took place roughly 150 hours after inoculation. The external load of each MFC was fixed at $1000 \Omega$ and the initial $\mathrm{pH}$ of the feed was adjusted to 6.9-7.0. The feed solution was replaced by a new one when the MFC voltage dropped below $50 \mathrm{mV}$. All the reactors were operated in an incubator at a temperature of $30 \pm 0.5^{\circ} \mathrm{C}$.

\section{Measurements and calculations}

A data acquisition system (PISO-813, ICP DAS Co., Ltd., Taiwan) was used to sample cell voltage every minute. Polarization curves were obtained by varying external resistances $\left(R_{e x}\right)$ from 1000 to $50 \Omega$ when the MFC operation became stable. Power and current densities were calculated using the effective anode surface area [5]. The Coulombic efficiency $\left(C_{E}\right)$ was calculated from the equation below [16],

$$
C_{E}=\frac{\sum_{i=1}^{n} U_{i} t_{i}}{R_{e x} F b(\Delta C O D) V} \times M
$$

in which $U_{\mathrm{i}}$ is the output voltage $(\mathrm{V})$ at time $t_{\mathrm{i}}, F$ is Faraday's constant $(96,485 \mathrm{C} / \mathrm{mol}), b$ the number of electrons exchanged per mole of oxygen $(=4), \triangle \mathrm{COD}$ the removal of Chemical Oxygen Demand (COD) in $\mathrm{mg} / \mathrm{L}, V$ the wastewater volume in $\mathrm{L}$, and $M$ the molecular weight of oxygen, respectively. COD was measured using a commercial COD detector (HACH, DRB 200, DR/890 Colorimeter, USA).

CV was performed on an electrochemical station (CHI600D, Shanghai Chenghua, Shanghai, China) in a standard three-electrode system at a rate of $50 \mathrm{mV} / \mathrm{s}$ ranged between -0.4 and $1.2 \mathrm{~V}$. The anode to be used in MFCs served as the working electrode, the counter electrode served as the cathode and the reference electrode was an SCE. A 0.5
$\mathrm{M} \mathrm{H}_{2} \mathrm{SO}_{4}$ solution was used as the electrolyte at room temperature for all the tests. Pure oxygen was passed through the solution for $20 \mathrm{~min}$ before redox measurements to make the solution oxygen saturated. A Field Emission Scanning Electron Microscope (FESEM, S-4700, Hitachi, Japan) was used to examine surface morphologies of the anodes before incubation.

The Electrochemical Impedance Spectroscope (EIS) was also conducted for the MFC systems on the electrochemical station. The MFC anode served as the working electrode and the cathode served as both the counter electrode and the reference electrode. The value of external bias voltage was the anode potential of MFC, usually ranging between -0.5 and $-0.4 \mathrm{~V}$. The impedance measurement was done in the range of $10^{5}-0.01 \mathrm{~Hz}$ with amplitude of $0.06 \mathrm{~V}$.

\section{Results and Discussion}

\section{Anode characterizations}

The SEM images of the graphite felt anodes are presented in figure 1. Compared with the bare surface of the unmodified anode, PPy films on the modified anodes are clearly seen. The PPy particles appeared to be rather uniform in particle diameter for each case. Particles aggregated together to form large grains. With a longer reaction time (i.e., more CV cycles), the particle diameter and film thickness both increased.

Figure 2 shows the $\mathrm{CV}(\mathrm{A})$ and the EIS (B) plots of the four anodes, respectively. Figure $2 \mathrm{~A}$ exhibits much higher redox currents on the modified anodes. This means that the modified anodes possessed much better electron-transfer abilities than the control. Figure 2B indicates that the ohmic resistance of Ppy-1 and Ppy-3 films were both $50 \Omega$. The PPy-2 film had the minimum ohmic resistance $(24 \Omega)$, which was lower than the control $(26 \Omega)$. This indicated that the polypyrrole film deposited on the anode by the electropolymerization reaction using 10 cycles CV cycles was most effective for promotion of electron transfer. The difference in ohmic resistance was likely related to the thinness of

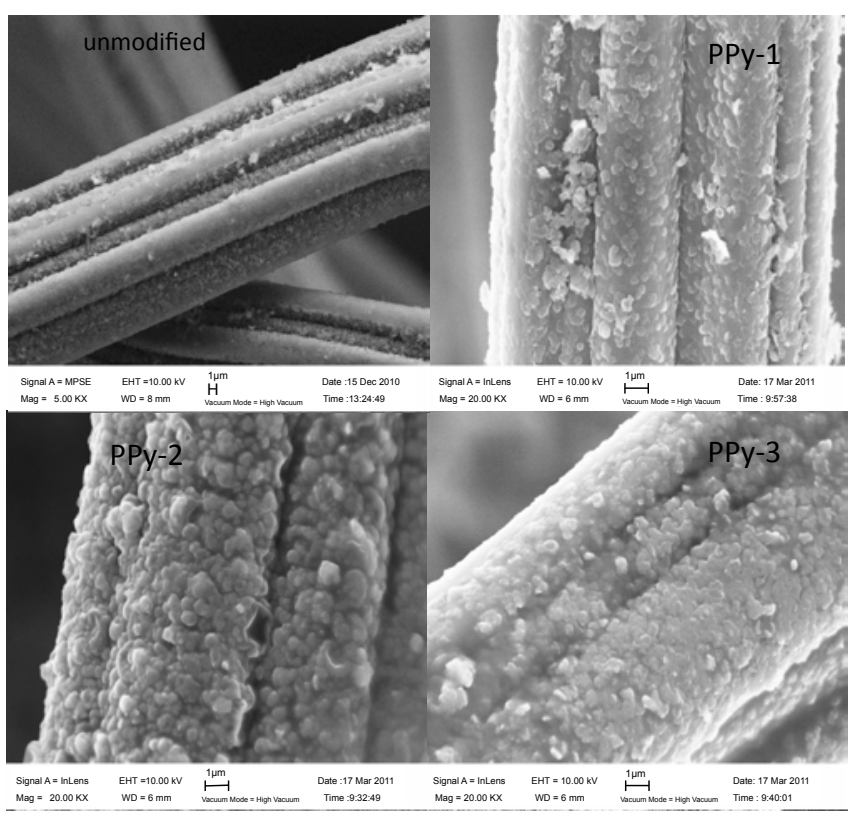

Figure 1: SEM images of the unmodified and modified anodes. 

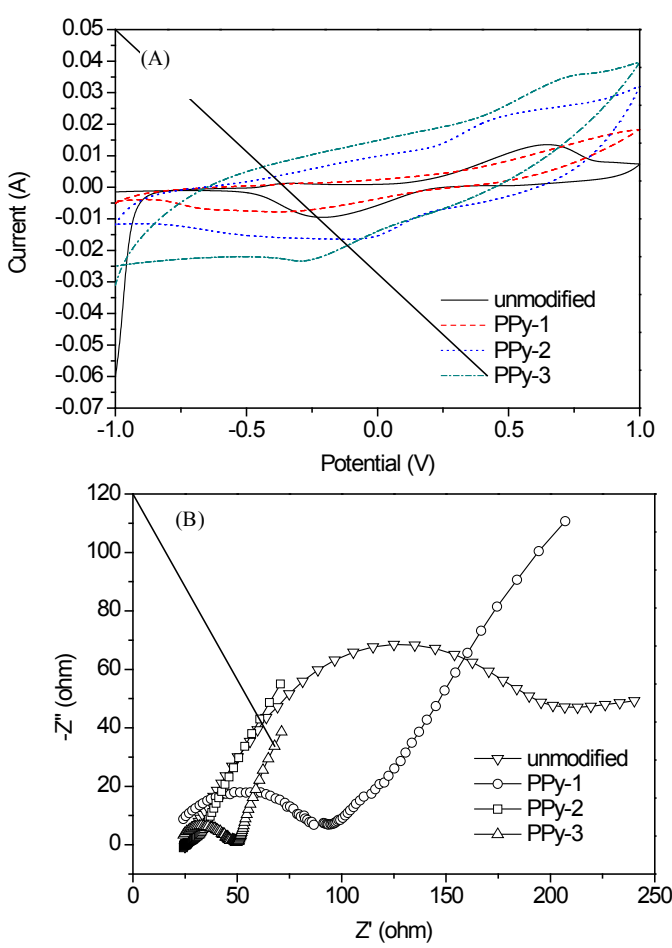

Figure 2: CV (A) and EIS (B) plots of four anodes.
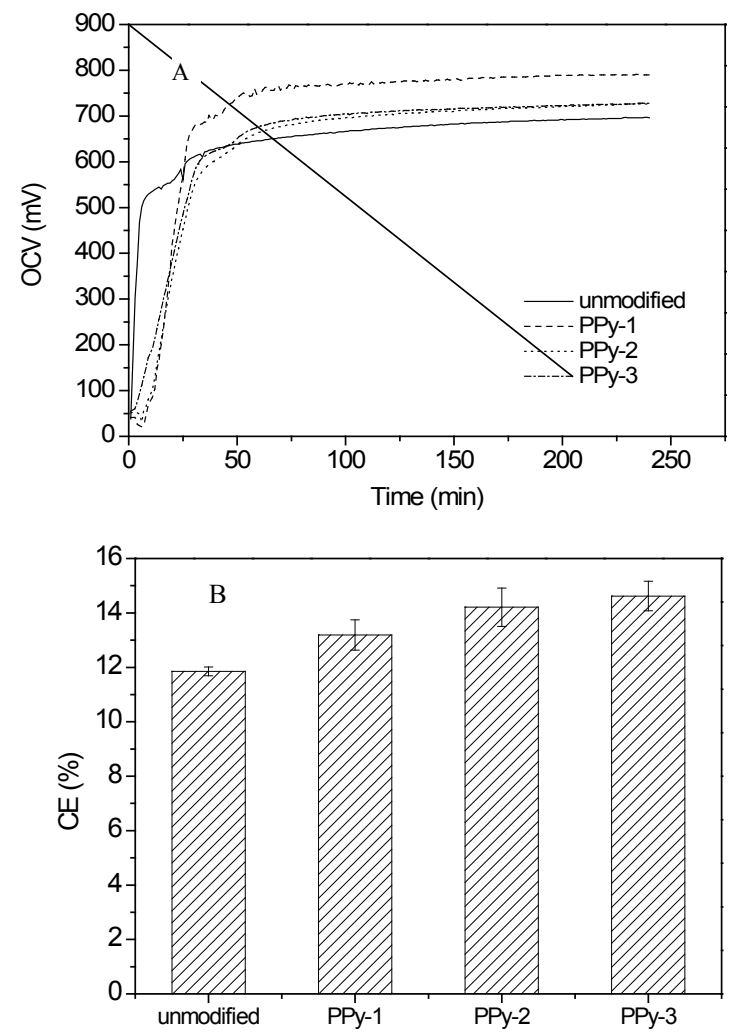

Figure 3: Open-circuit voltage (A) and Coulombic efficiency $(B)$ of the four MFCs after the anolyte replacement (glucose $1 \mathrm{~g} / \mathrm{L}$, external load $1000 \Omega$, initial $\mathrm{pH}$ 7).
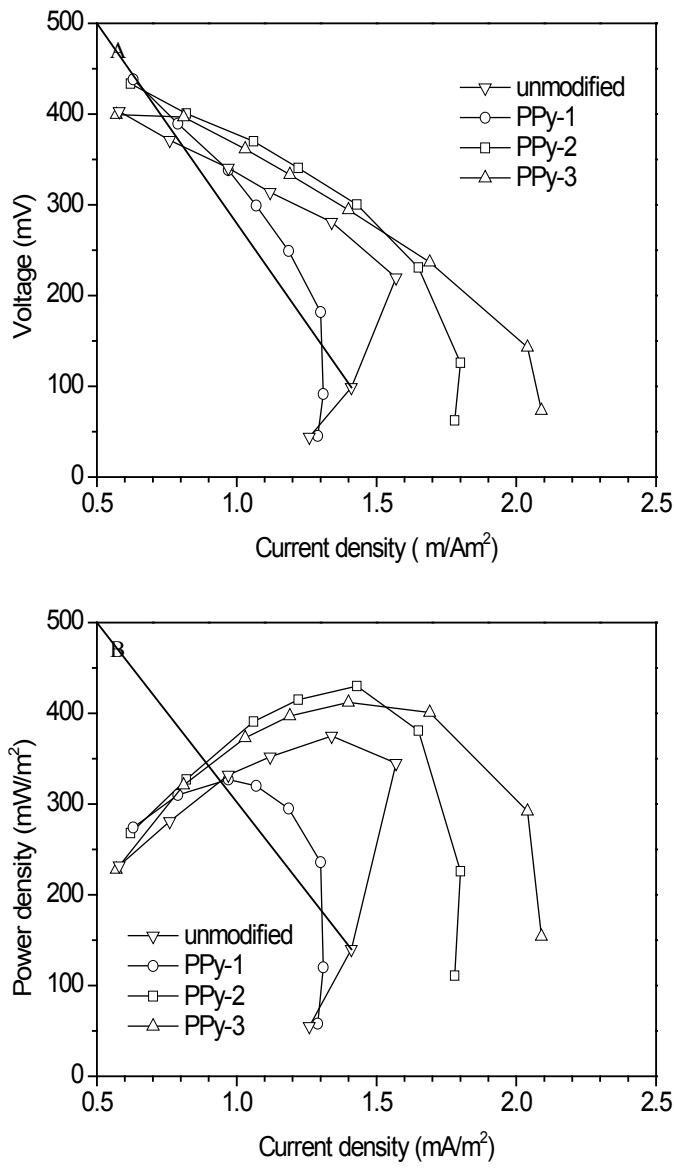

Figure 4: Polarization curves $(A)$ and power density curves $(B)$ as a function of current density for four MFCs.

the film, which was dependent on the number of CV cycles used during electropolymerization.

\section{Measurement of MFC performance}

Figure $3 \mathrm{~A}$ clearly demonstrates that the open-circuit voltages (OCVs) were higher than the control after the anode modification. Among the modified MFCs, the PPy-1 achieved the highest OCV of $790 \mathrm{mV}$ at about $60 \mathrm{~min}$, which was $100 \mathrm{mV}$ larger than that for the control $(690 \mathrm{mV})$. Electron recovery by the external circuit is a major indicator of MFC performance during substrate degradation, which is reflected by the Coulombic efficiency (Figure 3B). The Coulombic efficiency of the unmodified MFC was $11.9 \%$, and of its values for the three modified MFCs were 13.2\% (PPy-1), 14.2\% (PPy-2) and 14.6\% (PPy-3), respectively. Thus, the anode modification improved the MFC performance.

Figure 4 shows the polarization curves (A) and power density curves (B) for the four MFCs using steady discharging method [15] The anode modification increased the maximum output voltages of PPy- 1 and PPy-2 MFCs to $438 \mathrm{mV}$ and $434 \mathrm{mV}, 8.7 \%$ and $7.7 \%$ higher than that for the control $(403 \mathrm{mV})$, respectively. The maximum output voltage of the PPy-3 MFC was $399 \mathrm{mV}$, slightly lower than that for the control. Although the maximum output voltage of PPy-1 MFC was the highest at the beginning, the voltage dropped quickly with the change of the resistance. The power density of PPy-2 peaked at $430 \mathrm{~mW} / \mathrm{m}^{2}$, which was $15 \%$ higher than the control $\left(375 \mathrm{~mW} / \mathrm{m}^{2}\right)$. 
Citation: Chi M, He H, Wang H, Zhou M, Gu T (2013) Graphite Felt Anode Modified by Electropolymerization of Nano-Polypyrrole to Improve Microbial Fuel Cell (MFC) Production of Bioelectricity. J Microb Biochem Technol S12: 004. doi:10.4172/1948-5948.S12-004

\begin{tabular}{|l|c|c|c|c|c|}
\hline MFC & \multicolumn{5}{|c|}{ COD removal efficiency (\%) } \\
\hline Initial COD $(\mathrm{mg} / \mathrm{L})$ & 1010 & 1019 & 1023 & 1045 & average \\
\hline unmodified & 57.9 & 60.5 & 57.8 & 57.7 & 58.5 \\
\hline PPy-1 & 62.3 & 64.5 & 71.8 & 64.0 & 65.6 \\
\hline PPy-2 & 59.9 & 59.7 & 68.9 & 57.8 & 62.6 \\
\hline PPy-3 & 61.9 & 61.5 & 69.6 & 64.0 & 64.3 \\
\hline
\end{tabular}

Table 1: COD removal efficiencies of four MFCs.

Table 1 summarizes COD removal efficiencies before and after the anode modification. The average COD removal efficiencies after the anode modification were $65.6 \%, 61.6 \%$ and $64.3 \%$, all higher than that for the control (58.5\%).

\section{Conclusions}

This work showed that the electropolymerization method was an effective method to modify MFC anodes for improved MFC performance in terms of power generation and wastewater treatment (COD removal) efficiency. It was found that: (1) The graphite felt was successfully modified by nano-polypyrrole through electropolymerization and the reaction time increases led to thicker films, (2) the maximum output voltages of PPy-1 and PPy-2 MFCs were increased to $438 \mathrm{mV}$ and $434 \mathrm{mV}$, respectively compared with the $403 \mathrm{mV}$ for the control, and maximum power density of the PPy-2 MFC was $430 \mathrm{~mW} / \mathrm{m}^{2}$, a $15 \%$ increase compared with the control (375 $\left.\mathrm{mW} / \mathrm{m}^{2}\right)$, (3) the $\mathrm{CV}$ analysis showed that much higher redox currents on the PPy-2 and PPy-3 anodes, (4) the EIS analysis indicated that the ohmic resistance of the PPy-2 MFC was the lowest $(24 \Omega)$.

\section{Acknowledgements}

This work was financially supported by NCET (08-0296), SRF for ROCS SEM (2009-1001), GEFC09-12, and Natural Science Foundation of China (No. 51178225 and No. 21273120).

\section{References}

1. Logan BE, Hamelers B, Rozendal R, Schröder U, Keller J, et al. (2006) Microbial fuel cells: methodology and technology. Environ Sci Technol 40: 5181-5192.

2. Du Z, Li H, Gu T (2007) A state of the art review on microbial fuel cells: A promising technology for wastewater treatment and bioenergy. Biotechnol Adv 25: 464-482.

3. Harnisch F, Schröder U (2010) From MFC to MXC: chemical and biological cathodes and their potential for microbial bioelectrochemical systems. Chem Soc Rev 39: 4433-4448.

4. Zhou M, Chi M, Luo J, He H, Jin T (2011) An overview of electrode materials in microbial fuel cells. J Power Sources 196: 4427-4435.

5. Logan BE (2008) Anode materials, in: Microbial fuel cells, John Wiley \& Sons New Jersey, 62-68.

6. Watanabe K (2008) Recent developments in microbial fuel cell technologies for sustainable bioenergy. J Biosci Bioeng 106: 528-536.

7. Park DH, Zeikus JG (2003) Improved fuel cell and electrode designs for producing electricity from microbial degradation. Biotechnol Bioeng 81: 348355 .

8. Cheng S, Logan BE (2007) Ammonia treatment of carbon cloth anodes to enhance power generation of microbial fuel cells. Electrochem Commun 9 : 492-496.

9. Rosenbaum M, Zhao F, Quaas M, Wulff H, Schröder U, et al. (2007) Evaluation of catalytic properties of tungsten carbide for the anode of microbial fuel cells. Appl Catal B 74: 261-269.

10. Zhou MH, Chi ML, Wang HY, Jin T (2012) Anode modification by electrochemical oxidation: An alternative to improve the performance of microbial fuel cells. Biochem Eng J 60: 151-155.

11. Li YF (2004) Electrochemical properties of conducting polymers. J Fudan Univers (Nat Sci) 43: 468-481.

12. Zou Y, Pisciotta J, Baskakov IV (2010) Nanostructured polypyrrole-coated anode for sun-powered microbial fuel cells. Bioelectrochemistry 79: 50-56

13. Feng CH, Li FB, Liu HY, Lang X, Fan S (2010) A dual-chamber microbial fue cell with conductive film-modified anode and cathode and its application for the neutral electro-Fenton process. Electrochim Acta 55: 2048-2054.

14. Cai BH, Cao L, Wang ZJ (2010) Preparation, electrochemical properties, and application of polypyrrole. Chem Technol Market 33: 11-16.

15. Cheng S, Liu H, Logan BE (2006) Increased power generation in a continuous flow MFC with advective flow through the porous anode and reduced electrode spacing. Environ Sci Technol 40: 2426-2432.

16. Liang $P$, Fan $M Z$, Cao XX, Huang X, Wang C (2007) Composition and measurement of the apparent internal resistance in microbial fuel cell. Huan Jing Ke Xue 28: 1894-1898. 